\title{
Experiência da escrita: intervenção psicoterapêutica com mulheres em tratamento do câncer de mama
}

\author{
Alexandra Verardi Burlamaque \\ Ciomara Ribeiro da Silva Benincá ${ }^{* *}$
}

\section{Resumo}

O adoecer com câncer de mama provoca mudanças físicas e emocionais, causando sofrimento e um confronto com a possibilidade de morte e perdas. Esta pesquisa-intervenção de caráter qualitativo teve como objetivo subsidiar intervenções com mulheres em tratamento oncológico para o câncer de mama. A ideia foi utilizar a escrita compartilhada como estratégia psicoterapêutica que possibilita a expressão da subjetividade e o acesso aos conteúdos emocionais para ressignificá-los. Para tanto, foi proposta a duas mulheres diagnosticadas com câncer de mama, com 39 e 62 anos, respectivamente que, a partir da leitura de depoimentos publicados no blog da FEMAMA, escrevessem sobre a experiência oncológica em um diário ofertado a elas especialmente para esta finalidade. Esta intervenção aconteceu em um encontro individual com duração de uma hora e trinta minutos, nas dependências do ambulatório de oncologia de um hospital do norte gaúcho, sendo gravada e transcrita na íntegra. A análise qualitativa dos dados indica os benefícios psicoterapêuticos da escrita e do compartilhamento da experiência do diagnóstico e do tratamento do câncer de mama em prol do autoconhecimento e da potencialização de recursos psicológicos para o enfrentamento e superação das dificuldades decorrentes do adoecimento.

Palavras-chave: câncer de mama; oncologia; psicologia; escrita.

\section{Introdução}

A Organização Mundial de Saúde (OMS) afirma que câncer é o nome dado a um conjunto de mais de cem doenças que podem afetar praticamente qualquer parte do corpo, possuindo como principal característica o crescimento desordenado e a proliferação de células para além de seus limites habituais.

\footnotetext{
Psicóloga Oncológica. Especialista em Psicologia Hospitalar e Especialista em Psicologia Oncológica. Universidade de Passo Fundo (UPF) - Passo Fundo/ RS - E-mail: avburlamaque@gmail.com

** Doutora em Psicologia. Professora do Curso de Psicologia da Universidade de Passo Fundo (UPF) - Passo Fundo/RS - E-mail: beninca@upf.br
}

Data de submissão: ago. 2021 - Data de aceite: out. 2021 http://dx.doi.org/10.5335/rdes.v17i3.13013 
Naturalmente, para a maior parte das pessoas, o diagnóstico remete à ideia da morte, de mutilação e de dor, fazendo com que o câncer seja, historicamente, uma das doenças mais temidas. Todavia, o impacto gerado pelo diagnóstico se dá de acordo com a localização, com o grau de agressividade do tumor, o simbolismo do órgão afetado, o estágio da doença e o tratamento proposto (Andrade \& Azevedo, 2019; Magalhães et.al.2019).

A experiência do adoecimento, conforme Pereira e Calhão (2020), é vivenciada como um evento particular, ameaçador e arbitrário, que provoca uma ruptura na biografia do indivíduo. A partir dela, as certezas e as regras cotidianas são interrompidas para que o sujeito adentre numa realidade que não é corriqueira para si, caracterizada pela ameaça à vida e por preocupações e fantasias em relação ao diagnóstico, à possibilidade de mutilações e às perdas que estão implicadas no tratamento oncológico (Tavares \& Silveira, 2018).

Ao falar em câncer de mama, podemos encontrar presentes outras angústias ligadas a questões simbólicas e comumente importantes no universo feminino, já que o seio é um órgão repleto de significados culturais e psíquicos, como a sexualidade, a maternidade e a feminilidade (Marinho \& Amaral, 2017). Além disso, estudos de campo com pacientes em tratamento para o câncer de mama indicam que fatores como mudanças cor- porais, limitação de atividades rotineiras, comprometimento da autoimagem, preconceito e rejeição social podem gerar prejuízo nas relações interpessoais, tristeza e desesperança que podem culminar em depressão, ansiedade, angústia e medo (Scannavino et al., 2013; Pisoni et al., 2013; Sá \& Carozzo, 2018).

Nesse sentido, Santos e Souza (2019) destacam a importância do acompanhamento psicoterapêutico e da necessidade de se fomentar novas intervenções psicológicas ao paciente oncológico, em face às possíveis repercussões emocionais e psíquicas do diagnóstico e de seu tratamento, potencialmente mutilador e incitador de questões simbólicas e de identidade.

Dentre as novas possibilidades de intervenções psicológicas com pacientes que enfrentam o tratamento de uma doença grave, destaca-se a escrita como uma potencial intervenção. A ideia de compartilhar as próprias vivências com finalidade terapêutica remonta ao final do século XIX com o surgimento da Psicanálise, que instigava o indivíduo a refletir sobre suas vivências. Contudo, é apenas no final do século XX, com a popularização da internet, que esse hábito se fortaleceu com o surgimento dos blogs (do inglês weblog), por meio de plataformas gratuitas onde os usuários podiam criar suas páginas e falar de si, assumindo a função de "diário íntimo" on-line (Batista, 2008). 
A escrita de cunho biográfico e autobiográfico, conforme Gomes (2004), nas últimas décadas, tem sido intesificada e reconhecida como escrita de si. São cartas, diários íntimos e memórias que passaram a ter reconhecimento e visibilidade, tanto no contexto da academia quanto no mercado editorial e, mais recentemente, enquanto intervenção psicológica. $\mathrm{Na}$ prática clínica em psico-oncologia, para 0 mesmo autor, a escrita favorece a representação e projeção de si como forma de socorrer as demandas subjetivas e intersubjetivas que o sujeito traz junto consigo na vivência de adoecimento oncológico.

Segundo Paiva e Rasera (2016), o uso da escrita de cartas ou depoimentos vem sendo utilizada na prática clínica como recurso psicoterapêutico em diferentes formatos, sendo aplicado, nesta pesquisa, a proposta das participantes escreverem cartas para si ou direcionadas para terceiros. Este trabalho consiste em uma pesquisa-intervenção que utiliza a escrita como recurso psicoterapêutico junto a mulheres em tratamento para o câncer de mama. A ideia é subsidiar novas formas de intervenção psicológica e maximizar recursos disponíveis em consonância com as práticas sócioculturais contemporâneas.

Nessa ótica, propõe a escrita como instrumento legítimo de representação e de projeção de si e, também, como forma de ampliar a possibilidade de expressão das demandas subjetivas e intersubjeti- vas inerentes ao ser humano, portador de uma história de vida e identidade que lhe é única. Assim, com o estímulo à produção de cartas ou depoimentos no interior de um diário, experimenta-se, na psico-oncologia, uma nova forma de expressão do mundo interno e da subjetividade destas pacientes, possibilitando o acesso e a ressignificação dos conteúdos emocionais em prol do enfrentamento do processo de adoecimento e da promoção da saúde mental.

$\mathrm{O}$ aspecto terapêutico da experiência da escrita de cartas consiste, conforme Benetti e Oliveira (2016), na externalização de algo interno, tornando-o visível, palpável e compreensível, o que facilita o processo reflexivo e a ressignificação. Outrossim, escrever sobre experiências, sentimentos e pensamentos pode ter grande valor terapêutico, possivelmente, também, porque auxilia a examinar cada experiência a partir de vários ângulos, favorecendo a cognição e a resiliência (Sexton \& Pennebeker, 2009).

No contexto da clínica psicológica, a técnica de escrita terapêutica vem se mostrando benéfica e efetiva com pessoas que enfrentam diferentes doenças. Smyth, Stone, Hurewitz et al. (2000) utilizam-na em pesquisas com pacientes asmáticos, por exemplo, mostrando que os que escrevem têm menos crises do que aqueles que não o fazem. Peirie, Fontanilla, Thomas et al. (2004), da mesma forma, apontam o aumento da atividade 
das células imunológicas e a redução da carga viral com pacientes com AIDS, os quais são atribuídos às consequências do ato de escrever.

$\mathrm{Na}$ oncologia, pacientes que se dedicam a escrever sobre seus sentimentos, afirmam que são mais otimistas e apresentam melhorias em sua qualidade de vida (Stanton \& Danoff-Burg, 2002). Conclusões semelhantes foram obtidas por Chang, Huang e Lin (2013) em seus estudos com pacientes com câncer, que declararam se sentirem melhor mental e fisicamente depois de escrever sobre o que pensavam e sentiam em comparação com os que não o fizeram.

Nessa perspectiva, este trabalho desenvolveu uma proposta de intervenção psicológica com mulheres em tratamento oncológico do câncer de mama, buscando compreender como a escrita de um diário, inicialmente proposto pela redação de uma carta e/ou depoimento, pode ser utilizada como instrumento legítimo de representação e de projeção de si e, também, como forma de ampliar a possibilidade de expressão das demandas subjetivas e intersubjetivas inerentes ao ser humano, portador de uma história de vida e identidade que lhe é única.

\section{Metodologia}

Trata-se de uma pesquisa-intervenção de cunho qualitativo e de caráter descritivo-exploratório que buscou for- necer subsídios e novos entendimentos sobre possibilidades terapêuticas junto a mulheres portadoras de câncer de mama (Minayo, 1993). Neste estudo, tal metodologia possibilitou a compreensão da experiência do adoecimento e da sua expressão por meio da escrita enquanto forma de expressão, reflexão e compartilhamento.

O presente estudo utilizou-se de uma análise qualitativa baseada na teoria fenomenológica, que caracteriza-se por enfatizar a compreensão enquanto um processo dialógico, isto é, que implica tanto o pesquisador quanto as pessoas que estão servindo como objeto de pesquisa, ambos em sua condição de sujeito do processo (Gonzalez-Rey, 2002).

O estudo foi realizado no Ambulatório de Oncologia de um hospital de referência da região norte do Rio Grande do Sul, Brasil. Participaram deste estudo duas mulheres em tratamento oncológico para o câncer de mama que atenderam aos seguintes critérios: a) estar em tratamento oncológico para o câncer de mama do tipo radioterapia e quimioterapia; b) ter entre 30 e 65 anos de idade; c) ser alfabetizada; d) não apresentar sinais de comprometimento cognitivo e ou psiquiátrico; e) concordar em participar da pesquisa mediante assinatura do Termo de Consentimento Livre e Esclarecido (TCLE).

Foi realizada uma entrevista semi-estruturada de forma a resgatar a ex- 
periência do diagnóstico e do tratamento oncológico e, após, foi entregue um diário/ caderno exclusivamente elaborado para esta pesquisa, onde, nas primeiras páginas, foram inseridos cinco depoimentos impressos de mulheres em tratamento do câncer de mama publicados on-line no blog da FEMAMA. Os depoimentos foram selecionados por representarem a gama de sentimentos e emoções relacionadas ao câncer de mama, e por terem, as depoentes, idades próximas às participantes desta pesquisa. Também foi utilizado um questionário de avaliação elaborado para a pesquisa, com a finalidade de permitir que as pacientes manifestassem as suas opiniões sobre a intervenção realizada.

O projeto de pesquisa foi aprovado pelo Comitê de Ética em Pesquisa (CEP) sob número CAAE 30629020.1.0000.5342 e garantido a confidencialidade dos dados. As participantes foram selecionadas através de busca em prontuário e, após assinatura do TCLE, foram aplicados os instrumentos da pesquisa. O encontro individual gravado digitalmente foi realizado na salas de atendimento ambulatorial do hospital, com duração média de uma hora e meia.

Neste encontro, foi estabelecido rapport inicial e entregue o diário preparado para esta finalidade. Em seguida, foi realizada pela pequisadora a leitura em voz alta dos depoimentos das mulheres da FEMAMA, abrindo espaço para co- mentários e assinalamentos sobre a experiência pessoal de cada participante no diagnóstico e enfrentamento da doença em contraste com a das mulheres que publicaram suas histórias no referido blog, incentivando-se para que elas pudessem manifestar os fatores de identificação ou não, bem como as lições apreendidas com os depoimentos das mulheres em condições semelhantes as suas.

A partir das leituras, foi estimulado que as mulheres escrevessem de próprio punho, no diário, o seu relato a partir da pergunta estímulo "O que eu gostaria de compartilhar sobre a minha vivência com o câncer de mama?" Por fim, foi aplicado o instrumento avaliativo da intervenção. Ao mesmo tempo, foi investigado o significado desta experiência para cada paciente, a fim de avaliar a aplicabilidade da escrita terapêutica nas intervenções em saúde mental na oncologia. Foi sugerido, ainda, que quando desejassem, tornassem a acessar o site da FEMAMA a fim de avaliarem a possibilidade de também compartilharem as suas experiências no blog, anonimamente ou não.

As entrevistas realizadas com as participantes do estudo foram gravadas digitalmente para fins de transcrição e análise e, após, foram apagadas com o intuito de preservar o sigilo e anonimato das participantes. 


\section{Resultados}

Os dados decorrentes da transcrição e síntese dos depoimentos estão ilustrados por excertos das falas das pacientes, os quais estão destacados em itálico. Por motivos éticos, as pacientes não têm seus nomes revelados, sendo identificadas por personagens da literatura brasileira, a saber: Diadorim e Ana Terra, personagens que simbolizam mulheres protagonistas que, nas suas histórias, são reconhecidas pela força, determinação e coragem.

Ressalta-se, porém, que o texto construído na ordem cronológica, naturalmente, não traduz a sequência das falas, mas atende à necessidade de uma organização que permite a análise e a compreensão dos resultados obtidos, divididos em duas categorias: a história individual do adoecimento e a história comum compartilhada com as demais mulheres no enfrentamento do câncer de mama.

\section{A história individual do adoecimento}

Essa categoria reproduz a experiência individual das participantes, priorizando o sentido da experiência do adoecimento desde o diagnóstico até o momento atual, em que as pacientes estão realizando as sessões de quimioterapia e radioterapia. As falas foram retiradas da entrevista realizada antes da leitura dos depoimentos do blog e da escrita no diário.

Diadorim tem 62 anos, casada desde os vinte e mãe orgulhosa de quatro filhas. Natural e procedente de uma cidade de médio porte no interior do Rio Grande do Sul, trabalha como costureira. Compareceu ao encontro utilizando um lenço azul, com maquiagem marcante nos olhos, mostrando-se comunicativa e receptiva à proposta da pesquisa.

Ana Terra tem 39 anos, é casada e tem um filho pequeno, sendo natural e procedente de uma cidade de pequeno porte no interior do Rio Grande do Sul. Graduada em Pedagogia, descreveu seu trabalho como importante fator protetivo e de identidade. Compareceu ao local de realização da pesquisa utilizando lenço vermelho e, assim como Diadorim, destacavam-se os olhos maquiados e a comunicação fácil e fluída, com tendência a respostas mais bem contruídas e elaboradas em seus argumentos do que a outra participante.

Ambas iniciaram os relatos mediante solicitação da pesquisadora, com uma breve história de vida. A ideia foi contextualizar o momento do diagnóstico, as repercussões psicológicas, os significados da doença e do tratamento conforme o momento de vida. Diadorim caracterizou seu momento vital como estando "da metade para frente", mas "num momento da vida que a gente quer poder aproveitar a família". Ana Terra alegou que "quando 
a gente se considera nova é difícil conseguir pensar que existe a possibilidade de estar doente".

Ambas buscaram consultas médicas imediatas ao resultado dos exames, mesmo não considerando ainda a possibilidade de confirmação de um diagnóstico oncológico. Elas iniciaram os seus relatos a partir de informações objetivas como datas, locais e especificidades técnicas dos exames realizados. Como assevera Ana Terra: Hoje será a quarta radioterapia e faltarão somente dezesseis. Me tranquilizo contando quantas faltam.

As pacientes discorreram, também, sobre a necessidade de modificação de planos e sonhos pelo convívio próximo a uma doença potencialmente ameaçadora e culturalmente ainda associada à morte e ao sofrimento.

Ah, câncer para mim é pesado! Eu vejo que, nos dias de hoje, tem muita cura ou tratamento, mas o meu primeiro pensamento foi que eu iria morrer. (Diadorim, 62 anos).

Ouvir essa palavra é como se viesse alguém e tirasse toda a segurança que você acha que tem na vida. (Ana Terra, 39 anos).

Sobre o momento da confirmação do diagnóstico, ambas relataram sensações físicas que traduzem a reação de choque e estranhamento frente ao inesperado e desconhecido.
Eu não sabia se tinham me jogado um caminhão de gelo ou uma patrola em cima de mim. (Diadorim, 62 anos).

A sensação que eu tenho é que o chão se abriu e o céu desceu. Eu não lembro mais o que me disseram depois daquilo. (Ana Terra, 39 anos).

O medo do diagnóstico e dos sintomas da doença, conforme os depoimentos analisados, se deve não apenas às suas implicações físicas, mas também, à representação social que relaciona 0 câncer, em especial o de mama, à perda da feminilidade pelo ataque direto à vaidade das pacientes.

O meu medo era perder o cabelo e tudo aquilo que a perda do meu cabelo e possivelmente do meu seio representaria. Eu sempre fui muito vaidosa, cuidava do meu cabelo com carinho. Então, pensar em perder ele me deixou insegura (...) Quando caiu eu me senti não só doente, mas me senti feia! Não me reconhecia. Parecia que eu tinha perdido a minha identidade". (Ana Terra, 39 anos).

"Ah, a mama para a mulher é tudo! Seria uma das áreas mais importantes do nosso corpo, já que dali eu dei alimento para as minhas filhas". (Diadorim, 62 anos).

Sobre o enfrentamento da doença e dos sintomas decorrentes do tratamento, as pacientes ressaltaram a importância do apoio familiar e social como fonte de proteção, que favorece o desenvolvimento de comportamentos adaptativos e o fortalecimento da autoconfiança na 
superação das dificuldades advindas do diagnóstico de câncer de mama.

Eu tive certeza que eu não estaria sozinha. Depois do câncer eu não tenho mais aquele medo que me paralisava. Eu ensino o meu filho a confiar nas pessoas e na vida. (Ana Terra, 39 anos).

Minha família diz que sente orgulho de mim pela forma como eu venho tentando viver a doença e eu sempre digo para eles que eu vou tentar sempre. Tem horas que parece que a gente não vai aguentar! Isso tudo eu sinto, todo dia que venho aguentando. A gente aguenta, sim. (Diadorim, 62 anos).

\section{A história compartilhada do adoecimento}

A experiência de compartilhamento da história do diagnóstico, tratamento e enfrentamento do câncer de mama se deu em dois momentos complementares, a saber: a leitura dos depoimentos do blog da FEMAMA e a escrita no diário que foi ofertado às participantes.

Sobre a leitura dos depoimentos, percebeu-se reações de identificação imediata com os relatos publicados no blog e escolhidos para o presente estudo.

Eu achei este depoimento muito bonito, semelhante em muitas coisas com a minha história. (Diadorim, 62 anos).

Este depoimento tocou minha alma! Não sei se pela semelhança de idade, mas também pela forma como ela vem encarando a doença. (Ana Terra, 39 anos).
Um fator de importante identificação durante a leitura dos depoimentos se refere ao momento do diagnóstico do câncer de mama, sendo caracterizado como uma experiência de ruptura com o mundo presumido e seguro destas mulheres.

A gente leva um baque! $O$ jeito que ela se sentiu ouvindo o diagnóstico eu senti aqui também. (Diadorim, 62 anos).

Eu também fiquei muito revoltada e com a pergunta do por que comigo. Eu fiz uma revisão da minha vida toda até aquele momento, tentando entender se eu tinha feito algo tão grave que justificasse eu pensar que poderia perder a minha vida e não ver meu filho crescer. (Ana Terra, 39 anos).

Tanto Ana Terra quanto Diadorim puderam compartilhar, durante a leitura dos depoimentos, outros aspectos e elementos relacionados a suas experiências que não haviam sido trazidos durante a entrevista inicial, sugerindo a importância da leitura destes depoimentos para mobilizar outros conteúdos significativos para as participantes do estudo, como, por exemplo, o momento da perda dos cabelos após as primeiras sessões de quimioterapia.

Eu não te contei, mas a história dela é parecida com a minha, porque eu também pedi para as minhas filhas cortarem os meus cabelos quando eu vi que eles estavam começando a cair. Eu me fortaleci nelas. O meu cabelo representava tudo que eu gostava de cuidar. (Diadorim, 62 anos). 
Vê como somos diferentes e ao mesmo tempo muito semelhantes? O meu cabelo já começou a cair na primeira sessão e aqui te ouvindo eu sinto tudo que a P.G sentiu perdendo o cabelo dela. Como é difícil, como agride a gente. (Ana Terra, 39 anos).

É possível perceber que a alopecia se apresenta como um aspecto que vem concretizar o câncer de mama para estas mulheres, sendo a ausência de cabelos uma característica ainda muito associada aos pacientes oncológicos em tratamento.

Eu pensava que iria usar a peruca todos os dias para não chocar as pessoas, porque como ela diz no depoimento, todo mundo sabe que tu tens câncer quando te olha com um lenço, mas agora eu penso que de nada adianta eu fingir que não tenho nada. (Diadorim, 62 anos).

A questão da identificação entre a idade das participantes do estudo com as autoras dos depoimentos, também trouxe reações divergentes entre Ana Terra e Diadorim, como exemplificado nas falas abaixo.

Minha idade! Quero muito ouvir a história dela. (Ana Terra, 39 anos).

Meu Deus, tão nova! (Diadorim, 62 anos).

Além da idade do diagnóstico, as participantes também se identificaram com elementos relativos às estratégias de enfrentamento e à busca pela reorganização da vida após o diagnóstico.
Ela fala ali no final que a vida muda de sentido depois de um câncer. É verdade! Hoje em dia, eu consigo levar as coisas de outra forma, não precisa ser tudo ao pé da letra. Este depoimento me deixou pensando em algumas coisas que eu poderia fazer. (Diadorim, 62 anos).

Eu poderia ter lido esse depoimento logo após ter sido diagnosticada. Eu me identifiquei com a forma que ela encara a vida depois do tratamento. O que vai ficar comigo dessa leitura é a forma como ela se engajou na causa das mulheres com câncer. Eu não havia pensado nisso! (Ana Terra, 39 anos).

Percebeu-se que, ao final da realização da leitura de todos os depoimentos da FEMAMA, tanto Ana Terra quanto Diadorim trouxeram reflexões sobre possibilidades de engajamento em causas relacionadas ao câncer de mama:

Eu acho que eu poderia ter me beneficiado se tivesse lido histórias assim antes de iniciar o tratamento, porque quando comecei, parecia que eu era a única no mundo com câncer. Agora penso em poder me engajar em alguma causa que ajude as mulheres a se cuidarem mais, a fazer o autoexame. (Ana Terra, 39 anos).

Estes depoimentos me deixaram pensando sobre algumas coisas que eu poderia fazer. Quem sabe me engajar em alguma atividade no futuro com mulheres que vivem a mesma coisa que eu. (Diadorim, 62 anos). 
Após a leitura dos cinco depoimentos, foi iniciada a escrita de seus próprios relatos no caderno/diário. De início, percebeu-se a dificuldade de Diadorim e Ana Terra em iniciar a escrita de suas próprias narrativas, alegando dificuldade na atenção e concentração naquele momento. Mesmo assim, ambas manifestaram desejo pela escrita no diário, podendo, cada uma a sua maneira, expressar-se ao escrever e nomear suas vivências enquanto pacientes oncológicas.

Diadorim escreveu seu relato de forma mais objetiva, ressaltando aspectos concretos da experiência vivida, tais como a data e o tamanho do tumor, sem referir-se aos sentimentos implicados na descoberta do câncer.

Meu nome é Diadorim, 62 anos e, no dia 10 de maio de 2020, notei que tinha um caroço no seio. Então, fui na gineco e ela me mandou fazer uma mamografia e ultrassom, onde diagnosticou um caroço de $3,9 \times 1,9 \times 2,0$. Aí, fiz uma biópsia e veio o resultado. Câncer maligno. (Diadorim).

Ana Terra, por sua vez, em seu relato escrito trouxe detalhes sobre os sentimentos vivenciados no adoecimento, discorrendo abertamente sobre o impacto do diagnóstico, a fragilidade emocional e os sentimentos diante das perspectivas impostas pelo câncer de mama.

Meu nome é Ana Terra, sempre tive uma vida saudável, nunca bebi e nunca fumei. Em dezembro de 2019, prestes a completar 39 anos, descobri um carcinoma invasivo grau 3. Ninguém espera receber um diagnóstico desses e, no momento, o chão se abriu e o céu desceu! Pensei no meu filho e na minha mãe. Pensei, também, que poderia passar pela quimioterapia e ficar careca. Senti revolta! Já passava por um momento muito difícil: há uns dias havia perdido minha amada vovó por um câncer de pulmão. Enchi-me de coragem e dei a confirmação do diagnóstico para a minha mãe. Ah, que momento difícil! (Ana Terra).

Sobre a possibilidade de realizar a leitura dos depoimentos das outras mulheres que passaram por experiências semelhantes às suas no blog, ambas as participantes reconhecem nesta uma possibilidade de se projetar nas histórias contadas e, assim, poder revisar ideias e sentimentos em prol da ressignificação que permite $o$ amadurecimento e o crescimento pessoal.

Sou muito grata a Deus, à minha família toda, às pessoas que emanaram vibrações positivas, aos amigos que se aproximaram e aos que se afastaram. Quero agradecer pela oportunidade de contar a minha história e, quem sabe, servir de inspiração para quem passa por esse momento tão difícil. (Ana Terra, 39 anos).

Por fim, no questionário, ambas as participantes avaliaram positivamente a intervenção, reconhecendo este como um momento valioso para conhecer a experiência de outras mulheres, além de poder avaliar a sua própria história de adoecimento e enfrentamento da doença. Ao final, as duas também manifestaram o desejo de levar consigo o diário para 
seguir escrevendo quando estivessem em casa e dispostas ao exercício reflexivo.

Eu sinto que a leitura dos depoimentos me deu um pouco mais de coragem também para eu escrever, vendo que posso, também, servir de exemplo para outras mulheres. Com o diário eu tenho um espaço para o desabafo. (Ana Terra, 39 anos).

Através da escrita posso desabafar o que é difícil relatar falando. (Diadorim, 62 anos).

\section{Discussão}

Conforme os dados obtidos no presente trabalho, dentre as principais preocupações das mulheres ao receberem um diagnóstico de câncer de mama está a própria sobrevivência. Estudos semelhantes indicam que, em seguida ao choque da notícia do adoecimento, surge a preocupação com o tratamento e as condições para realizá-lo, bem como as inquietações quanto à possibilidade de mutilação, desfiguração e possíveis consequências para a vida sexual e social (Carver, 1993; Duarte \& Andrade, 2003; Marinho \& Amaral, 2020), este último representado no preconceito, no estigma social, que afeta de forma dramática as mulheres acometidas pelo câncer de mama (Vieira et.al, 2020).

Quanto às consequências psicossociais do diagnóstico oncológico, estudos prospectivos que avaliaram a qualidade de vida de mulheres submetidas a tratamento quimioterápico e mastectomia, demonstraram prejuízos não só à imagem corporal, mas também limitações na vida sexual, no trabalho e até nos hábitos e atividades de vida diária (Engel et al., 2004; Ganz et al., 2004), alguns que, também, foram relatados pelas pacientes participantes desta pesquisa.

Da mesma forma, relatos sobre o significado do membro afetado pelo câncer também foram obtidos nesta e em outras investigações com pacientes oncológicas. No depoimento de Diadorim, por exemplo, pode-se identificar que a vivência do câncer alojado na mama reforça a ideia da localidade vinculada à vivência da feminilidade, como a maternidade e a sexualidade. Nessa mesma linha, estudos demonstram que a localização diagnóstica causa medos e crises nas mulheres, posto que, no imaginário social, o seio é associado a atos prazerosos, como amamentar, seduzir e acariciar, não combinando com a ideia de ser objeto de possíveis intervenções dolorosas, ainda que necessárias (Brochonski et.al, 2017 ).

Sobre as intervenções terapêuticas, as participantes desse estudo assumiram os medos e preocupações relacionadas às mudanças decorrentes do adoecimento e do caráter invasivo do tratamento. Para Silva (2019), as rupturas e a desestabilidade representaram marcas singulares na história das pacientes, afetando sua identidade, rompendo suas certezas e convocando a necessidade de novos arranjos, prioridades, valores e 
posicionamentos frente à vida. Nesse cenário, a família é uma base segura de suporte e apoio, representando a fonte de informação e a estruturação dos vínculos afetivos fundamentais no processo de adaptação e enfrentamento do câncer, esclarecem Godinho e De Arruda (2018), tal como destacado pelas participantes.

Além da rede do suporte social e familiar, também é importante dispor de estatégias terapêuticas especializadas para dar conta do apoio psicológico necessário a pacientes que enfrentam a crise do adoecimento. $\mathrm{O}$ diagnóstico e o tratamento do câncer de mama gera impacto nas esferas cognitiva, emocional, comportamental e social, interferindo negativamente na percepção e na atribuição de significado que reverte a suposta ordem do mundo presumido do indivíduo.

O acompanhamento psicológico, nesta situação, vem na tentativa de auxiliar o paciente a restaurar esse significado, recuperar o equilíbrio e restabelecer as circunstâncias de vida anteriores à ocorrência de uma situação traumática, como exposto por Tavares e Silveira (2018). As abordagens terapêuticas, então, auxiliam os pacientes a identificar novos recursos de enfrentamento em face à doença, na medida em que oferece apoio e informação de forma ativa, visando contribuir na redução do sentimento de isolamento, além de ajudar a desenvol- ver novas habilidades na resolução de problemas (Dos Santos \& Souza, 2019).

$\mathrm{Na}$ presente pesquisa, especificamente, foi investigada a efetividade do compartilhamento da experiência do diagnóstico e tratamento do câncer como estratégia de apoio psicológico, sendo os resultados positivos aqui obtidos reforçados por vários autores (Queiroz et.al.2020; Santos, 2017; Bittar et.al.2018). Flores e Quintana (2016) reforçam o papel do grupo e das trocas coletivas como meio de enfrentamento efetivo capaz de amenizar os sentimentos desconfortáveis associados a ameaças e perdas, normalmente vinculadas aos processos de adoecimento e, no caso do câncer de mama, não deixando de considerar o caráter universal de algumas angústias associadas ao contexto da doença.

Em investigação sobre experiências de compartilhamento grupal realizada por De Souza (2016) com mulheres em tratamento do câncer de mama, os significados atribuídos por elas foram de partilha de sentimentos, de mecanismo de solução de problemas, de ambiente educativo e de espaço interativo que oportuniza amizades. No trabalho aqui realizado, a experiência de compartilhamento não se deu na prática, mas, sim, de forma simbólica a partir da leitura dos depoimentos de pacientes com câncer de mama publicados e da decorrente reflexão realizada sobre pontos comuns 
da história de adoecimento e do enfrentamento da crise. Neste caso, a escrita, e, não, a fala, serviu como facilitador da identificação e partilha, na medida em que a leitura dos relatos de outras mulheres diagnosticadas e tratadas para o câncer de mama, estimulou a escrever e refletir sobre a própria trajetória da doença e busca da cura.

A respeito do papel terapêutico da escrita, Pennebaker (2018) discorre que quando os indivíduos transformam os seus pensamentos e sentimentos diante de experiências disruptivas em palavras, a sua saúde física e emocional tende a melhorar significativamente. Dentro disso, o processo de escrita constitui-se como um caminho possível, tendo repercussões ao nível dos efeitos negativos associados à experiência de um trauma e conduzindo a melhorias nas dimensões sociais, psicológicas, comportamentais e biológicas dos indivíduos.

$\mathrm{O}$ ato de escrever pode, em si, trazer um universo de possibilidades e propor outras formas de olhar e agir sobre determinadas situações, principalmente quando trabalhado em contexto psicoterapêutico, possibilitando ampliar e dar sentido ao que é escrito (Pennebaker, 2018). A escrita terapêutica ou expressiva ajuda os pacientes a pensar de maneiras diferentes sobre as suas experiências dolorosas, permitindo-lhes fazer reavaliações, o que origina mu- danças cognitivas e emocionais, como as relatadas por Ana Terra.

A presente proposta de estimular as mulheres a contar as suas experiências com o câncer de mama, mesmo que no âmbito das anotações privadas como cartas ou diário pessoal, possibilitou a apropriação gradual da tarefa da escrita terapêutica como forma de revisitar e reescrever as suas narrativas quantas vezes lhes for necessário. Nesse sentido, as participantes aderiram à tarefa da escrita, o que, como processo terapêutico, facilitou a ressignificação e o redimensionamento da experiência com o câncer de mama pela externalização da mesma na forma de texto.

$\mathrm{O}$ produto oriundo desse processo comunicativo, isto é, o texto escrito, torna-se, em si mesmo, um instrumento terapêutico que pode ser reutilizado para fins reflexivos tanto de forma privada quanto compartilhado em diferentes âmbitos, inclusive publicado na internet para servir a outras mulheres que enfrentam a mesma situação, reafirmando o significado compartilhado do adoecimento.

À medida que Diadorim e Ana Terra foram escrevendo e narrando as suas emoções e sentimentos sobre os acontecimentos vivenciados no percurso do adoecimento oncológico, puderam, como as pacientes de outros estudos, reorganizar, assimilar e atribuir um novo significado a estas vivências (Baikie \& 
Wilhelm, 2005; Figueiras \& Marcelino, 2008).

Nesse processo de ressignificação, investigações sustentaram a premissa de que escrever sobre vivências desafiadoras tem consequências benéficas para o bem-estar individual, indicando melhoria nos níveis de saúde mental da população que faz uso da escrita de si. $\mathrm{O}$ ato de escrever, muitas vezes, pode ser libertador, atuando como estratégia comunicativa que implica ou provoca compromisso de mudança positiva, superação de dificuldades (Bennett et al., 2005; Pereira e Ponciano, 2019) alívio da ansiedade e diminuição do sofrimento psicológico ocasionado pela crise como as enfrentadas pelas mulheres dignosticadas com câncer de mama.

\section{Considerações finais}

O presente estudo avaliou as possibilidades da escrita de si como instrumento comunicativo e psicoterapêutico no enfrentamento do diagnóstico e tratamento do câncer de mama. As pacientes avaliaram positivamente a experiência da escrita na forma de cartas ou diário, motivadas pela leitura de depoimentos de outras mulheres em situação de vida semelhante, o que remete ao valor do compartilhamento das ideias e sentimentos, tendo a identificação com os iguais uma forma de ressignificar o processo de adoecimento e de potencializar os recursos psicológicos de enfrentamento e superação da crise.

Considere-se, porém, que as estratégias de intervenção psicológica devem levar em conta a singularidade do processo de adoecimento permeado pelos recursos psicossociais, cognitivos e culturais do paciente. Assim, sugere-se que estudos correlacionais sejam realizados em larga escala a fim de comprovar os benefícios da escrita terapêutica no acompanhamento psicológico das mulheres com câncer de mama, dimensionando as suas possibilidades e limitações. Saliente-se, ainda, que iniciativas que multipliquem os recursos terapêuticos disponíveis para além dos atendimentos psicológicos tradicionais são sempre necessárias, considerando a importância da manutenção da saúde mental do paciente e da necessária qualificação do trabalho do psicólogo na oncologia.

\section{Writing experience: psychotherapeutic intervention with women undergoing breast cancer treatment}

\section{Abstract}

Getting sick with breast cancer causes physical and emotional changes, causing suffering and a confrontation with the possibility of death and loss. This research was a qualitative intervention that aimed subsidize interventions with women undergoing cancer treatment for breast cancer. 
The idea was to use shared writing as a psychotherapeutic strategy that allows the expression of subjectivity and the access to emotional contents to reframe them. For this purpose, it was proposed to two women diagnosed with breast cancer, aged 39 and 62 , respectively, who, from reading testimonials published on the FEMAMA blog, to write about the cancer experience in a diary offered to them especially for this purpose. This intervention took place in an individual meeting lasting approximately one hour and thirty minutes, on the premises of the oncology outpatient clinic of a hospital in the north of Rio Grande do Sul, being recorded and transcribed. The qualitative analysis of the data indicates the psychotherapeutic benefits of writing and sharing the experience of the diagnosis and treatment of breast cancer in favor of self-knowledge and the enhancement of psychological resources for coping and overcoming the difficulties resulting from illness.

Keywords: breast cancer; oncology; psychology; writing.

\section{Referências}

ANDRADE, A. M. R. DE, \& DE AZEVEDO, J. M. H.. O impacto do diagnóstico oncológico: contribuições da Terapia Cognitivo-Comportamental. Revista Científica Hospital Santa Izabel, 2(3), 36-40, 2019. Acesso em: 28 de setembro, 2020. Dsponível em: https://doi. org/10.35753/rchsi.v2i3.109

BAIKIE, K. A., \& WILHELM, K.. Emotional and physical health benefits of expressive writing. Advances in psychiatric treatment, 11(5), 338-346, 2005. Acesso em 02 de agosto, 2020. Disponível em: https://doi.org/10.1192/ apt.11.5.338
BATISTA, P. P.. Do diário ao blog confessional: continuidade ou o surgimento de uma nova prática?. Contemporânea (Título não-corrente), 6(3), 105-118, 2008. Acesso em: 10 de outubro, 2020. Disponível em: https://doi. org/10.12957/contemporanea.2008.17259

BENNETT, P., WILLIAMS, Y., PAGE, N., HOOD, K., WOOLLARD, M., \& VETTER, N.. Associations between organizational and incident factors and emotional distress in emergency ambulance personnel. British journal of clinical psychology, 44(2), 215-226, 2005. Acesso em 12 de agosto, 2020. Disponível em: de https://doi.org/10.1348/014466505X29639

BENETTI, I. C., \& DE OLIVEIRA, W. F.. O poder terapêutico da escrita: quando o silêncio fala alto. Cadernos Brasileiros de Saúde Mental / Brazilian Journal of Mental Health, 8(19), 67-76, 2016. Acesso em 2 de julho, 2020. Disponível em: http://stat.ijkem.incubadora.ufsc.br/ index.php/cbsm/article/view/3452

BITTAR, C. M. L., CASSIANO, R. L., \& SILVA, L. N.. Espiritualidade e religiosidade como estratégia de enfrentamento do câncer de mama: relato de um grupo de paciente. Mudanças-Psicologia da Saúde, 26(2), 25-31, 2018. Acesso em 5 de julho, 2020. Disponível em: https://doi. org/10.15603/2176-1019/mud.v26n2p25-31

BROCHONSKI, J. W., DE ALMEIDA RODRIGUES, S., MANZOTTI, C. A. S., \& BERNUCI, M. P. (2017). Perfil das mulheres diagnosticadas com câncer de mama no município de Maringá-PR. Saúde e Pesquisa ISSN 2176-9206, 10(1), 51-59, 2017. Acesso em 12 de maio, 2020. Disponível em: https://doi.org/10.17765/2176-9206.2017v10n1p51-59

CARVER, S. C.. How coping mediates the effects of optimism on distress: A study of woman with early stage breast cancer. Journal of Personality and Social Psychology, 65(2), 375-389, 1993. Acesso em 13 de junho, 2020. Disponível em: 10.1037//0022-3514.65.2.375

CHANG, J. H., HUANG, C. L., \& LIN, Y. C.. The psychological displacement paradigm in diary-writing (PDPD) and its psychological benefits. Journal of Happiness Studies, 14(1), 
155-167, 2013. Acesso em 12 de outubro, 2020. Disponível em: https://doi.org/10.1007/s10902012-9321-y

DUARTE, T. P. \& ANDRADE, A. N.. Enfrentando a mastectomia: análise dos relatos de mulheres mastectomizadas sobre questões ligadas à sexualidade. Estudos de Psicologia, 8(1), 155-163, 2003. Acesso em: de junho, 2020. Disponível em: https://doi.org/10.1590/S1413-294X2003000100017.

ENGEL, J, KERR, J, SCHLESINGER-RAAB, A, SAUER, H \& HÖLZEL, D.. Quality of life following breast-conserving therapy or mastectomy: Results of a 5-year prospective study. Breast Journal, 10(3), 223-231, 2004. Acesso em 2 de agosto, 2020. Disponível em: 10.1111/j.1075$-122 X .2004 .21323 . x$

FIGUEIRAS, M. J., \& MARCELINO, D.. Escrita terapêutica em contexto de saúde: Uma breve revisão. Análise Psicológica, 26(2), 327-334, 2008. Acesso em 25 de agosto, 2020. Disponível em: https://doi.org/10.14417/ap.497

FLORES, L. B., \& QUINTANA, A. M.. Utilização de grupos de sala de espera como estratégia de apoio psicológico para pacientes onco-mastológicos. Seminário Nacional Demandas Sociais e Políticas Públicas na Sociedade Contemporânea., 2016. Acesso em 12 de junho, 2020. Disponível em: de https://online.unisc.br/acadnet/ anais/index.php/snpp/article/view/14682

GANZ, P. A., LORNA, K., STANTON, A., KRUPNIK, J. L., ROWLAND, J. H., MEYEROWITZ, B. E., BOWER, J. E. \& BELIN, T. R.. Quality of life at the end of primary treatment of breast cancer: First results from the moving beyond cancer randomized trial. Journal of the National Cancer Institute, 96(5), 376-387, 2004. Acesso em 2 de junho, 2020. Disponível em: 10.1093/jnci/djh060

GOMES, A. M. D. C.. Escrita de si, escrita da história. São Paulo: Editora FGV, 2004.

GODINHO, V. R. T., \& DE ARRUDA, A. L.. A influência do suporte familiar no processo de recuperação de mulheres com câncer de mama. Revista FAROL, 7(7), 5-21, 2018. Acesso em 12 de julho, 2020. Disponível em: http:// www.revistafarol.com.br/index.php/farol/article/view/144

REY, F. L. G.. Pesquisa Qualitativa em Psicologia-caminhos e desafios. São Paulo: Cengage Learning Editores, 2002.

JUNQUEIRA, L. C. U., \& DOS SANTOS, M. A.. Atravessando a tormenta: imagem corporal e sexualidade da mulher após o câncer de mama. Revista Família, Ciclos de Vida e Saúde no Contexto Social, 8, 562-574, 2020. Acesso em 01 de junho, 2020.Disponível em: https://doi. org/10.18554/refacs.v8i0.4669

MARINHO, V. L., \& DO AMARAL, L. R. O. G.. Mulheres mastectomizadas: sentimentos e significados diante do diagnóstico e autoimagem. REVISTA CEREUS, 9(2), 154-169, 2017. Acesso em 7 de julho, 2020. Disponível em: http://www.ojs.unirg.edu.br/index.php/1/ article/view/1551

MARINHO, V. L., \& DO AMARAL, L. R. O. G.. Mastectomia e seus impactos na sexualidade feminina. Revista Educação, Psicologia e Interfaces, 4(3). Acesso em 12 de agosto, 2020. Diaponível em: https://doi.org/10.37444/issn2594-5343.v4i4.292

MAGALHÃES, L. D. A., CLAAS, M. L., KONZEN, L. T., BORGES, L. M., FERRARI, M., \& ZACHARIAS, D. G.. O diagnóstico de câncer e a importância do acompanhamento psicológico: relato de um caso clínico. Anais do Salão de Ensino e de Extensão, 71, 2019.

MINAYO, M. C. D. S., \& SANCHES, O.. Quantitativo-qualitativo: oposição ou complementaridade?. Cadernos de saúde pública, 9(3), 237-248, 1993. Acesso em 10 de agosto, 2020. Disponível em: https://doi.org/10.1590/S0102-311X1993000300002

PENNEBAKER, J. W.. Expressive writing in psychological science. Perspectives on Psychological Science, 13(2), 226-229, 2018. Acesso em 10 de julho, 2020. Disponível em: https:// doi.org/10.1177/1745691617707315

PEREIRA, L. R. R., \& CALHAO, A. R. P.. Para além do câncer de mama: estudo centrado nas 
mulheres em tratamento quimioterápico. Revista do NUFEN, 12(2), 40-60, 2020. Acesso em: 12 de outubro, 2020. Disponível em: http://pepsic. bvsalud.org/scielo.php?script=sci_arttext\&pid =S217525912020000200003\&lng=pt\&nrm=iso

PISONI, A. C., KOLANKIEWICZ, A. C. B., SCARTON, J., LORO, M. M., DE SOUZA, M. M., \& SÁ, G. S., \& CAROZZO, N. P. P.. Imagem corporal e habilidades sociais em pacientes com câncer de mama. Revista de Psicologia da IMED, 10(1), 37-55, 2018. Acesso em 12 de outubro, 2020. Disponível em: https://doi. org/10.18256/2175-5027.2018.v10i1.2493

SANTOS, M. A. D., \& SOUZA, C. D.. Intervenções Grupais para Mulheres com Câncer de Mama: Desafios e Possibilidades. Psicologia: Teoria e Pesquisa, 35, 2019. Acesso em 25 de junho, 2020. Disponível em: http://dx.doi. org/10.1590/0102.3772e35410

SCANNAVINO, C. S. S., SORATO, D. B., LIMA, M. P., FRANCO, A. H. J., MARTINS, M. P., MORAIS JÚNIOR, J. C, VALÉRIO, N. I.. Psico-Oncologia: atuação do psicólogo no Hospital de Câncer de Barretos. Psicologia USP, 24(1), 35-53, 2013. Acesso em 12 de junho, 2020. Disponível em: https://doi.org/10.1590/ S0103-65642013000100003

SEXTON, J. D., \& PENNEBAKER, J. W.. The healing powers of expressive writing. The psychology of creative writing, 264-273, 2009.

SMYTH, J. M., STONE, A. A., HUREWITZ, A., \& KAELL, A.. Effects of writing about stressful experiences on symptom reduction in patients with asthma or rheumatoid arthritis: A randomized trial. Jama, 281(14), 1304-1309, 1999. Acesso em 9 de agosto, 2020. Disponível em: http://pascal-francis.inist.fr/vibad/index.ph $\mathrm{p}$ ?action=getRecordDetail\&idt $=1750171$

SOUZA, C. DE.. Percepção de Mulheres com Câncer de Mama Acerca do Grupo de Apoio: Dando Sentido à Experiência Compartilhada. Tese de doutorado. Universidade de São Paulo, 2016, São Paulo.

STONE, A. A., SMYTH, J. M., KAELL, A., \& HUREWITZ, A.. Structured writing about stressful events: Exploring potential psychological mediators of positive health effects. $\mathrm{He}$ alth Psychology, 19(6), 619, 2000. Acesso em 12 de agosto, 2020. Disponível em: https://doi. org/10.1037/0278-6133.19.6.619

TAVARES, S., \& SILVEIRA, J.. Processo de aceitação e de enfrentamento da mulher diagnosticada com câncer de mama. REVISTA CONGREGA-MOSTRA DE TRABALHOS DE CONCLUSÃO DE CURSO-ISSN 2595-3605, (2), 654-669, 2018.

VIEIRA, A. A., GARCIA, B., SARILHO, D., DA SILVA, G. G. D., BROCCO, S. M. M., DA COSTA GONÇALVES, A., \& DE VASCONCELOS, E. C. L. M.. Qualidade de vida de mulheres submetidas ao tratamento do câncer de mama: estudo transversal. Revista Interdisciplinar de Saúde e Educação, 1(1), 35-55, 2020. Acesso em 12 de junho, 2020. Disponível em: https://periodicos. baraodemaua.br/index.php/cse/article/view/32 